\title{
Variantes lexicais para cigarro de palha no português falado por indígenas na Amazônia brasileira
}

\author{
Lexical variants for cigarro de palha in portuguese spoken by \\ indigenous people in the Brazilian Amazon
}

\author{
Romário Duarte Sanches ${ }^{1}$ \\ https://orcid.org/0000-0002-0571-303X
}

DOI: $10.26512 /$ rbla.v12i1.28485

Recebido em dezembro/2019 e aceito em abril/2020

\section{Resumo}

Este artigo apresenta as variantes lexicais do item cigarro de palha no português falado por indígenas na Amazônia brasileira. Para isso, foram consultados trabalhos de natureza geolinguística realizados em área indígena como Rodrigues (2017), Costa (2018), Alves (2018), Félix (2019) e Sanches (2020). Esses estudos estão dentro do escopo da dialetologia pluridimensional e relacional e da geolinguística (Thun 2000; Cardoso 2010). Os resultados apontam a ocorrência de 13 variantes lexicais usadas por indígenas para denominar cigarro de palha no Norte do Brasil: porronca, cigarro de fumo, cigarro de tabaco, cigarro de palha, tauarí (tavari), fumo de corda, coringa, barurí, maratá, cigarro de abade, casca de árvore, arapiraca e charuto.

Palavras-chave: Dialetologia. Geolinguística. Português indígena. Variação lexical.

\begin{abstract}
This article aims to present the lexical variants of Portuguese, referring to the item cigarro de palha, spoke by indigenous people in the Brazilian Amazon. To achieve this purpose, works of geolinguistic nature in indigenous areas were consulted, such as Rodrigues (2017), Costa (2018), Alves (2018), Félix (2019) and Sanches (2020). These studies are within the scope of multidimensional and relational dialectology and geolinguistics (Thun 2000; Cardoso 2010). The results point to the occurrence of 13 lexical variants used by indigenous people to denominate cigarro de palha in northern Brazil: porronca, cigarro de fumo, cigarro de tabaco, cigarro de palha, tauari (tavarí), fumo de corda, coringa, barurí, maratá, cigarro de abade, casca de árvore, arapiraca and charuto.
\end{abstract}

Keywords: Dialectology. Geolinguistics. Indigenous Portuguese. Lexical Variation.

1 Linguista, Professor Substituto da Universidade do Estado do Amapá - UEAP. E-mail: romario.duarte@gmail.com. 


\section{Introdução}

Os estudos geolinguísticos ou geossociolinguísticos realizados na região Norte do Brasil, sobretudo em área indígena, têm mostrado uma configuração linguística, no que tange à variação lexical, ora convergente ora divergente dos resultados já descritos e mapeados nas capitais ou cidades urbanas da região. Isso se deve à natureza heterogênea das línguas, isto é, o princípio de variação e de mudança inerente a elas. Esta premissa é sustentada por sociolinguistas e dialetólogos que entendem a variação linguística como objeto de estudo motivado por princípios e parâmetros internos e externos ao sistema linguístico.

No caso dos fatores extralinguísticos, estes podem resultar em uma classificação bem diversificada para variação, a depender do contexto como o aspecto geográfico que pode resultar na variação diatópica, a faixa etária na variação diageracional, a escolaridade na variação diastrática, a religião na variação diarreligiosa, o contato entre línguas na variação dialingual e entre outros tipos.

Com base nessa discussão sobre variação linguística, o objetivo deste estudo é apresentar as variantes lexicais para o item cigarro de palha no português falado em áreas indígenas na Amazônia brasileira. Assim, foram consultados trabalhos geolinguísticos realizados em área indígena como o estudo de Rodrigues (2017) que diz respeito ao português falado na Terra Indígena Wajãpi, o de Costa (2018) que discute o português falado em áreas indígenas de língua Tupi-Guarani nos estados do Pará e Maranhão, o de Alves (2018) sobre o português falado em Terras Indígenas (TI) do estado do Pará (TI Asuriní do Xingu e TI Araweté), o de Félix (2019) que apresenta o português em contato com as línguas Nheengatu, Baniwa e Tucano em São Gabriel da Cachoeira (AM) e o de Sanches (2020) que estuda o português e o kheuól falado por indígenas da etnia Karipuna do Amapá, na região do Oiapoque-AP.

Estes estudos investigam a variação lexical do português falado por indígenas em suas respectivas terras. São trabalhos recentes que trazem à tona o polimorfismo linguístico na Amazônia brasileira que ora podem gerar agrupamentos/contínuos de variantes lexicais convergentes ou divergentes, cabendo ao linguista à tentativa de explicar esses fenômenos.

\section{Variantes lexicais para cigarro de palha no Brasil}

O estudo da variação lexical no Brasil, por meio da dialetologia pluridimensional e relacional (Thun 2000) e da geolinguística pluridimensional (Cardoso 2010) ${ }^{2}$, tem sido recorrente nessas últimas três décadas. A maioria desses estudos foi impulsionada pelo banco de dados e pela proposta

2 Trata-se do cruzamento de dados diastráticos, diagenéricos, diageracionais, diarreferenciais, diamésicos etc., aos dados diatópicos da geolinguística tradicional. 
metodológica do Projeto Atlas Linguístico do Brasil - ALiB que vem contribuindo amplamente com a formação de novos pesquisadores na área, trazendo um vasto conhecimento científico sobre o português brasileiro, em seus diversos níveis, além do lexical, como: semântico, fonológico, fonético, morfológico, sintático, discursivo, pragmático e entre outros. São inúmeros trabalhos desenvolvidos e orientados/coordenados pelos diretores científicos do referido projeto. Entre esses trabalhos encontram-se os atlas linguísticos, os artigos científicos, as teses, as dissertações e as monografias.

Com base no banco de dados do $\mathrm{ALiB}^{3}$, foi possível identificar a distribuição geossocial ${ }^{4}$ do item lexical cigarro de palha em todo território nacional. No estudo de Razky e Costa (2014), por exemplo, eles analisam a pergunta "145 - CIGARRO DE PALHA - Que nomes dão ao cigarro que as pessoas faziam antigamente enrolado à mão?". De acordo com os autores, o referido item apresentou 21 variantes lexicais na fala dos colaboradores entrevistados nas capitais brasileiras. As variantes mais mencionadas foram: cigarro de palha, porronca, cigarro de fumo, palheiro e tabaco. Numa análise diatópica os autores destacaram a variante cigarro de palha que foi mencionada em todas as regiões com destaque para a região Centro-Sul do Brasil ${ }^{5}$, onde houve certa concentração da variante.

$\mathrm{Na}$ análise das variantes por regiões, Razky e Costa (2014) mostram que na região Norte, cigarro de palha e tabaco são as mais frequentes. Enquanto no Nordeste tem-se a predominância de cigarro de fumo. Já na região Centro-Sul destaca-se a variante palheiro. Essa distribuição consta na Carta L16 do Atlas Linguístico do Brasil (cf. Figura 01).

Nota-se na carta linguística seguinte que há certa delimitação espacial do uso de algumas variantes, como foi analisado e descrito por Razky e Costa (2014). Em uma análise diastrática, levando em consideração a faixa etária, os autores demonstram que a variante tabaco ocorreu somente na fala dos colaboradores mais jovens.

3 Para saber mais sobre a proposta metodológica do projeto consultar o volume 1 do Atlas Linguístico do Brasil (Cardoso et al., 2014).

4 Termo cunhado por Razky e Sanches (2016) para falar de análise geossociolinguística, isto é, uma análise que contemple a variação geográfica e a variação social dos fenômenos linguísticos (idade, sexo, faixa etária etc.).

5 A região geoeconômica Centro-Sul abrange os estados das regiões Sul e Sudeste (com exceção do norte de Minas Gerais), além dos estados de Mato Grosso do Sul, sul do Tocantins e o do Mato grosso, e Distrito Federal. 
Figura 01 - Carta linguística L16

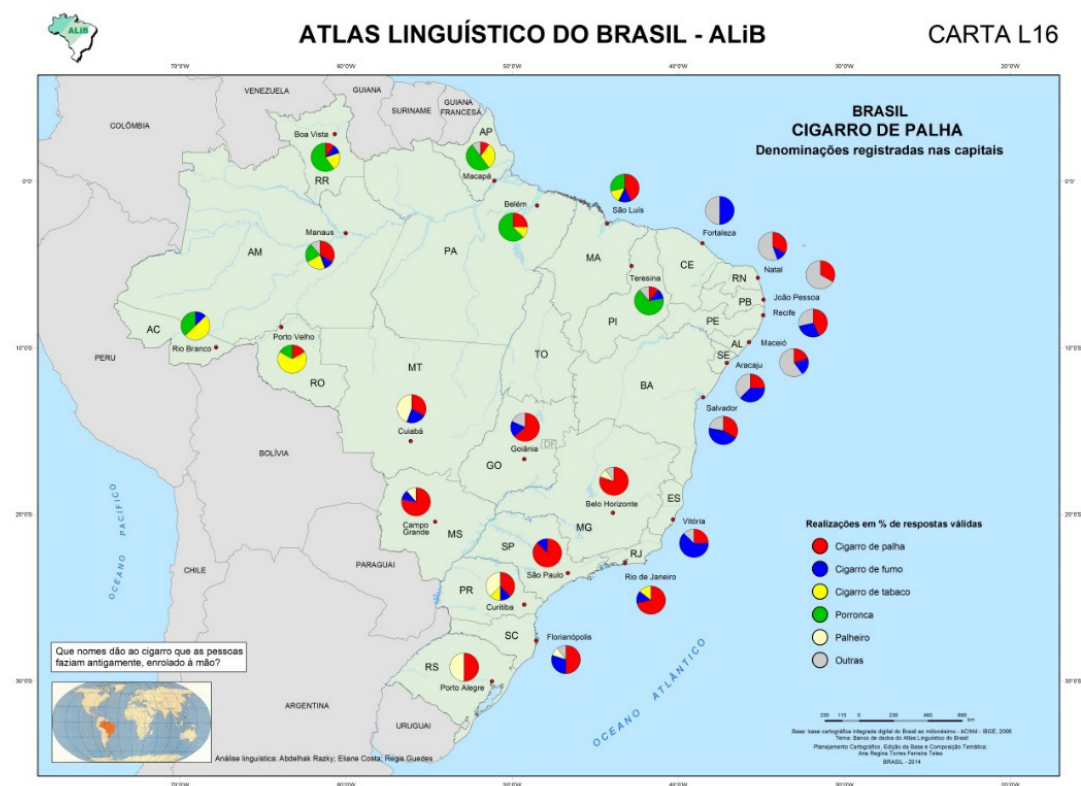

Fonte: Extraída do Atlas Linguístico do Brasil (Cardoso et al., 2014)

No que diz respeito à variável sexo, Razky e Costa (2014) afirmam que as cinco variantes mais frequentes podem ocorrer independentemente da variável sexo. Já em relação à variável escolaridade, as variantes cigarro de palha $\mathrm{e}$ porronca podem caracterizar, numa mesma proporção, o falar dos colaboradores de ensino fundamental e superior.

Consultando outros atlas linguísticos, na intenção de comparar as variantes encontradas para cigarro de palha, constatou-se que no Atlas Linguístico de Pernambuco (Sá 2013) há as seguintes variantes mapeadas: cigarro de fumo, cigarro de corda, cigarro de palha e pacaia. No Atlas Linguístico Pluridimensional do Português Paulista (Figueiredo Júnior 2019:299) há a ocorrência de variantes como cigarro de palha, palheiro, cigarro de fumo e fumo de corda.

No que tange ao Norte do Brasil, no Atlas Linguístico do Amazonas (Cruz 2004), encontram-se porronca, tabacão/tabaco, cigarro, cigarro de tabaco, tabacá, cigarro de palha, cigarro de onça, cigarro de moe e brejeiro. No Atlas Linguístico do Sul Amazonense (Galvão 2018) há registros de cigarro de palha, palheiro, cigarro de fumo, cigarro de corda, cigarro de tabaco, porronca, pito, pacaia, cigarro de papel, mata-rato, boró/bororó, brejeiro, pé-de-burro e péduro. No Atlas Linguístico Topodinâmico e Topoestático do Estado do Tocantins (Silva 2019) foram identificadas as variantes porronca, cigarro e palha, fumo (bravo, de corda, de rolo, de tora, de beira de rio), palheiro/palhoso, tabaco, pito e charuto. Já no Atlas Linguístico do Amapá (Razky, Ribeiro e Sanches 
2017) foram mapeadas as variantes tabaco, porronca, charuto, cigarro de palha e trevo.

Em relação às variantes lexicais para cigarro de palha cartografadas no ALiB, sobretudo na região Norte, em comparação com os dados encontrados nos atlas do Amapá, Tocantins, Amazonas e do Sul Amazonense, fica evidente um certo contínuo lexical, isto é, a convergência da amostra dos dados do ALiB com os dados de outros atlas na mesma região geográfica.

A CARTA L16, Figura 01, registrou as variantes cigarro de palha, cigarro de fumo, cigarro de tabaco e porronca na região Norte, e estas também aparecem no Amapá 6 , Tocantins e no Amazonas. De modo geral, pode-se inferir que porronca, nesta perspectiva da geolinguística urbana, é uma variante lexical padrão, pois ocorre de forma predominante nas capitais do Norte do Brasil, não havendo registro em outras regiões (exceto no Nordeste, na capital Teresina - PI). No entanto, cabe aqui questionar se essa configuração lexical converge ou não com as variantes lexicais encontradas para cigarro de palha no espaço geográfico indígena da região Norte do Brasil.

\section{Métodos da pesquisa geolinguística em comunidades indígenas}

Para que seja possível responder ao questionamento feito na seção anterior, é necessário identificar e entender os procedimentos metodológicos das pesquisas geolinguísticas já realizadas em comunidades indígenas da Amazônia brasileira.

O levantamento de variantes lexicais para o item cigarro de palha em área indígena foi feito por meio da consulta ao corpus linguístico de três teses de doutorado e duas dissertações de mestrado, trabalhos vinculados à Universidade Federal do Pará (UFPA). As pesquisas que serão apresentadas a seguir foram selecionadas com base em três critérios: 1) são trabalhos de cunho geolinguístico, possibilitando a intercomparação dos dados; 2) permitem consultar o item lexical estudado, isto é, registraram e/ou mapearam as variantes lexicais para cigarro de palha; e, 3) são estudos com foco na variação lexical do português falado em área indígena.

O primeiro trabalho é a Tese de Doutorado de Eliane Oliveira da Costa, defendida em 2018. A Tese tem como título "Estudo geossociolinguístico do léxico do português falado em áreas indígenas de língua Tupi-Guarani nos estados do Pará e Maranhão". O objetivo foi investigar a variação lexical do português falado em áreas indígenas de língua Tupí-Guaraní sob a abordagem da Dialetologia Pluridimensional. Assim, a autora selecionou quatro Terras Indígenas, a saber: TI Trocará (etnia Asuriní do Tocantins/PA), TI Nova Jacundá (etnia Guarani Mbyá/PA), TI Sororó (etnia Suruí Aikewára/PA) e TI Cana Brava (etnia Guajajára/MA), controlando em sua pesquisa as dimensões diatópica, diageracional, diastrática, diagenérica e dialingual. Em suma, Costa

6 Cigarro de fumo não apareceu no ALAP, mas foi encontrado no trabalho de Matos (2020). 
(2018) mapeou cerca de 50 itens lexicais do português de contato com línguas Tupi-Guarani.

O segundo trabalho, defendido em 2019, é a Tese de Doutorado de Maria Ivanete de Santana Felix com o título "Estudo geossociolinguístico do léxico do português falados pelos Baré, Tukano e Baniwa em São Gabriel da Cachoeira (AM)". A autora investigou a variação lexical do português falado pelos indígenas falantes das línguas Nheengatu, Tukano e Baniwa. Para a pesquisa, ela utilizou o modelo de Dialetologia Pluridimensional, controlando as dimensões: diatópica, diageracional, diassexual e diastrática. Felix (2019) elaborou 160 mapas linguísticos evidenciando aspectos lexicais do português falado por indígenas da região de São Gabriel da Cachoeira, no Amazonas.

O trabalho mais recente é a Tese de Doutorado de Romário Duarte Sanches, defendida em 2020, intitulada "Microatlas Linguístico (português-kheuól) da área indígena Karipuna do Amapá". A metodologia empregada pelo autor diz respeito à Dialetologia Pluridimensional e Contatual. Para pesquisa foram selecionadas nove aldeias Karipuna e 36 colaboradores indígenas bilíngues. Em cada localidade foram entrevistados quatro falantes indígenas. O produto da pesquisa resultou em 102 cartas linguísticas que mostram as variantes lexicais do português e do kheuól (variedade crioula de base francesa).

Em relação às duas dissertações de mestrado, tem-se a primeira defendida em 2017, intitulada "Mapeamento lexical do português falado pelos Wajãpi no Estado do Amapá: uma abordagem geossociolinguística", de Maria Doraci Guedes Rodrigues. Seu objetivo foi mapear e descrever a variação lexical do português falado na Terra Indígena Wajãpi, no estado do Amapá. O estudo adotou o modelo da Geolinguística e da Dialetologia Pluridimensional. Para cada ponto foram entrevistados quatro colaboradores indígenas: dois homens e duas mulheres, com faixa etária distinta. Rodrigues (2017) cartografou 20 itens lexicais do Português falado em cinco comunidades da etnia Wajãpi.

O último trabalho, a Dissertação de Mestrado, defendida em 2018, de Fábio Luidy de Oliveira Alves, intitulada "Estudo geossociolinguístico do português em contato com as línguas Asuriní do Xingu e Araweté". O autor buscou descrever os aspectos semântico-lexicais da variedade do português falado em Terras Indígenas (TI) do estado Pará, como a TI Asuriní do Xingu e a TI Araweté. O trabalho adotou a Dialetologia Pluridimensional, levando em consideração as dimensões: diatópica, diageracional e diassexual. O estudo conta com quatro pontos de inquérito, onde foram entrevistados quatro colaboradores em cada localidade, totalizando assim 16 colaboradores. Ao final, a pesquisa contou com a elaboração de 46 cartas linguísticas. 


\section{Denominações para cigarro de palha em áreas indígenas da Amazônia brasileira}

Antes de apresentar os resultados é importante retomar as informações contidas na Figura 01 (cf. seção 2), CARTA L16 do ALiB, que registrou como variantes recorrentes na fala de colaboradores não indígenas, nas capitais dos estados da região Norte, as seguintes lexias: cigarro de palha, cigarro de fumo, cigarro de tabaco e porronca. Destaca-se que esta última variante foi classificada aqui como variante lexical padrão, uma vez que porronca ocorreu de forma predominante na fala de colaboradores residentes nas capitais do Norte do Brasil.

$\mathrm{Na}$ tentativa de responder ao questionamento deixado na segunda seção deste trabalho, serão apresentadas as variantes lexicais para cigarro de palha nas comunidades indígenas localizadas nos estados do Pará, Maranhão, Amazonas e Amapá. O objetivo é verificar se a configuração lexical apresentada nas capitais da região Norte converge com as variantes lexicais encontradas em comunidades indígenas da Amazônia brasileira.

O primeiro trabalho a ser comparado diz respeito aos dados da tese de doutorado de Eliane Oliveira da Costa. O estudo foi feito nas áreas indígenas de língua Tupi-Guarani nos estados do Pará e Maranhão, especificamente nas Terras Indígenas Trocará (etnia Asuriní do Tocantins/PA), Nova Jacundá (etnia Guarani Mbyá/PA), Sororó (etnia Suruí Aikewára/PA) e Cana Brava (etnia Guajajára/MA).

Costa (2018) elaborou a carta lexical CL017 que mostra as denominações encontradas para cigarro de palha nas comunidades indígenas supracitadas.

Figura 02 - Carta linguística CL017

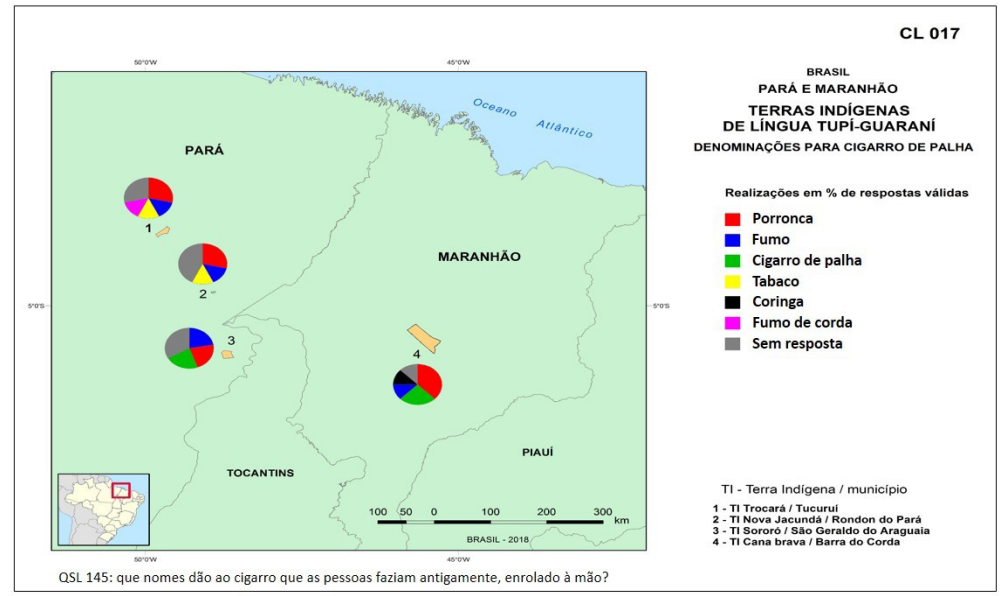

Fonte: Extraída de Costa (2018). 
Com base na Figura 02, a autora mostra que na TI Trocará (ponto 1), os indígenas denominam cigarro de palha como porronca, fumo, tabaco e fumo de corda. Na TI Nova Jacundá (ponto 2) eles mencionam porronca, fumo e tabaco. $\mathrm{Na}$ TI Sororó (ponto 03), eles conhecem porronca, fumo e cigarro de palha. $\mathrm{E}$ na última, TI Cana brava (ponto 04), eles disseram porronca, fumo, cigarro de palha e coringa. Os dados de Costa (2018) revelam que porronca é a variante padrão nessas TI's pesquisadas.

Já no trabalho de Felix (2019), a autora fez um levantamento de variantes lexicais do português falado por indígenas em São Gabriel da Cachoeira, no Amazonas. As etnias pesquisadas foram Baré, Tukano e Baniwa.

Figura 03 - Carta lexical 023

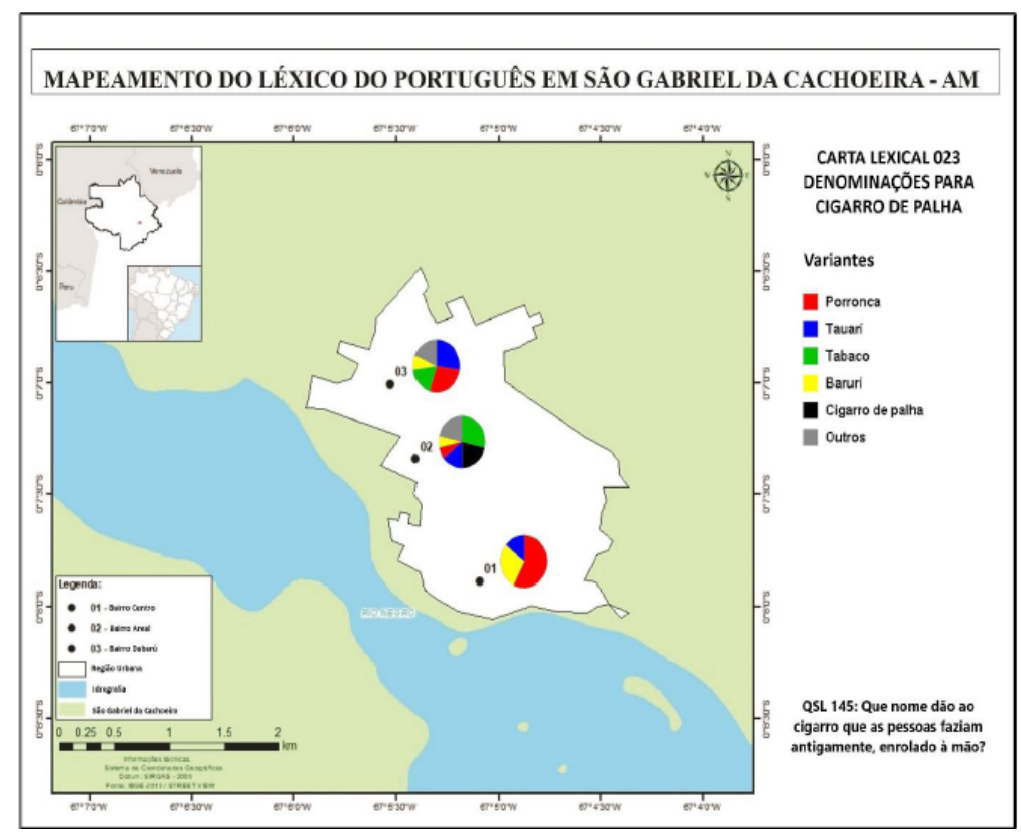

Fonte: Extraída de Félix (2019).

Conforme a Figura 03, no ponto 01, Bairro Centro, os colaboradores indígenas conhecem porronca, tauarí, tabaco e baruri. No ponto 02, Bairro Areal, eles mencionaram tabaco, cigarro de palha, tauarí, porronca e baruri. No último ponto, Bairro Dabarú, os indígenas disseram porronca, barurí e tauarí. Em síntese, os dados de Félix (2018) mostram que porronca é a variante padrão nas comunidades pesquisadas em São Gabriel da Cachoeira (AM).

O trabalho consultado, a seguir, é o de Alves (2018) que mapeou variantes lexicais do português falado por indígenas das etnias Assuriní do Xingu e Araweté, no Pará (PA). A carta lexical abaixo ilustra as variantes encontradas para o item lexical cigarro de palha. 
Figura 04 - Carta linguística L27

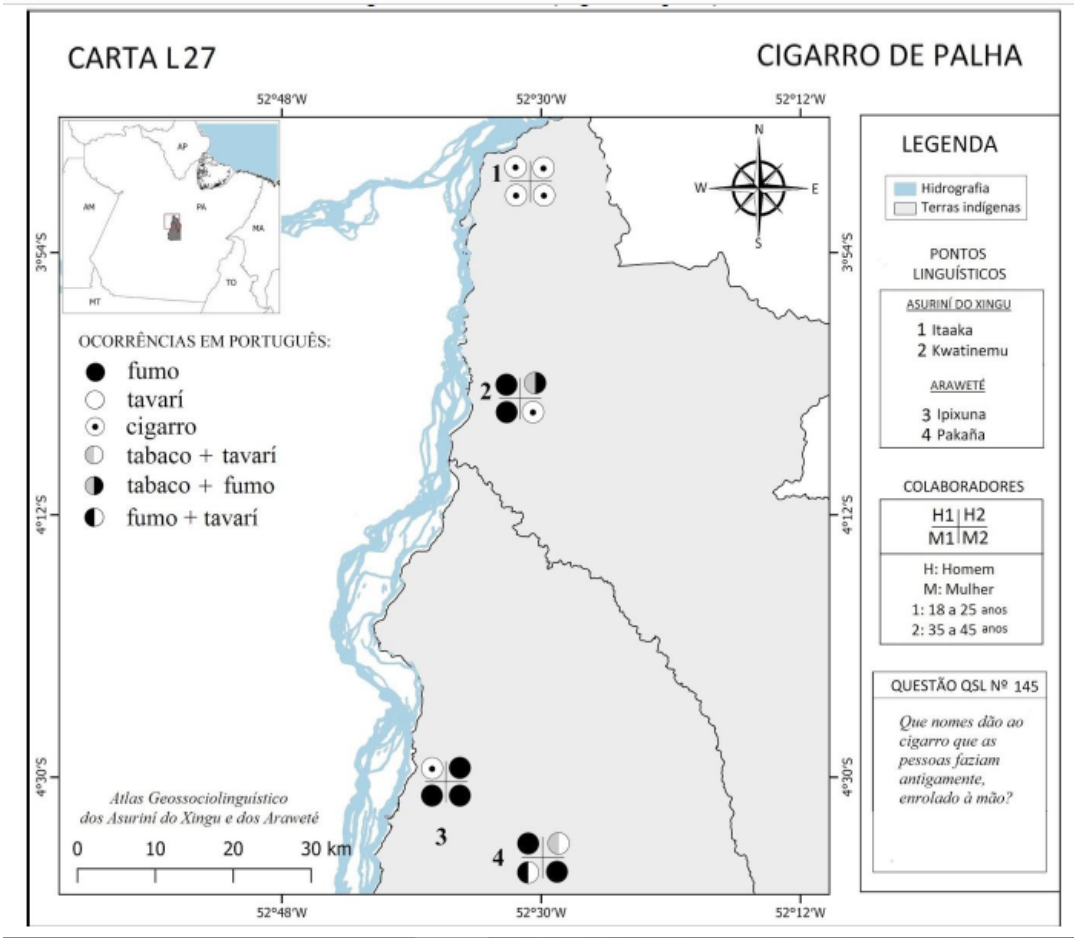

Fonte: Extraída de Alves (2018).

Com base na Figura 04, o autor registrou as seguintes ocorrências lexicais em português para cigarro de palha: fumo, tavarí, cigarro e tabaco. No ponto 01, comunidade Ataaka, foi mencionada somente a variante cigarro. No ponto 02, comunidade Kwatinemu, o autor encontrou as variantes fumo, tabaco e cigarro. No ponto 03, comunidade Ipixuna, apareceram fumo e cigarro. E, por último, ponto 04, comunidade Pakaña, os colaboradores mencionaram fumo, tavarí e tabaco. De modo geral, a variante lexical mais recorrente nessas comunidades foi fumo, seguido de cigarro.

Outro estudo importante a ser mencionado aqui é o de Rodrigues (2017) que mapeou variantes lexicais do português falado por indígenas Wajãpi, no Amapá (AP). Ressalta-se que para o item cigarro de palha, a autora não elaborou um mapa específico, no entanto, foi possível consultar o banco de dados da pesquisa, possibilitando identificar as variantes lexicais encontradas.

O estudo de Rodrigues (2017) aponta que na Terra Indígena Wajãpi foram registradas as variantes: maratá, cigarro de palha, cigarro de abade, tabaco, casca da árvore, arapiraca, cigarro. No ponto 01, comunidade Aramirã, as variantes mencionadas foram maratá, cigarro de palha e cigarro de abade. No ponto 02, comunidade Pairakae, os colaboradores disseram conhecer cigarro de palha e tabaco. No ponto 03, comunidade CTA, eles mencionaram cigarro de 
palha, cigarro de abade e casca da árvore. No ponto 04, comunidade Mariry, eles denominaram como cigarro de palha, tabaco e Arapiraca. E, no ponto 05, comunidade Kurani'yty, foi registrada apenas a variante tabaco. Deste modo, percebe-se que a variante mais frequente falada na etnia Wajãpi para denominar "um tipo de cigarro enrolado à mão" foi cigarro de palha, seguido de tabaco.

O último trabalho a ser destacado aqui é o Sanches (2020) que buscou descrever e mapear variantes lexicais tanto em português como em kheuól, variedades faladas pelo povo indígena Karipuna do Amapá, localizado ao extremo norte do estado do Amapá, na região do Oiapoque.

Figura 05 - Carta P77 (cigarro de palha)

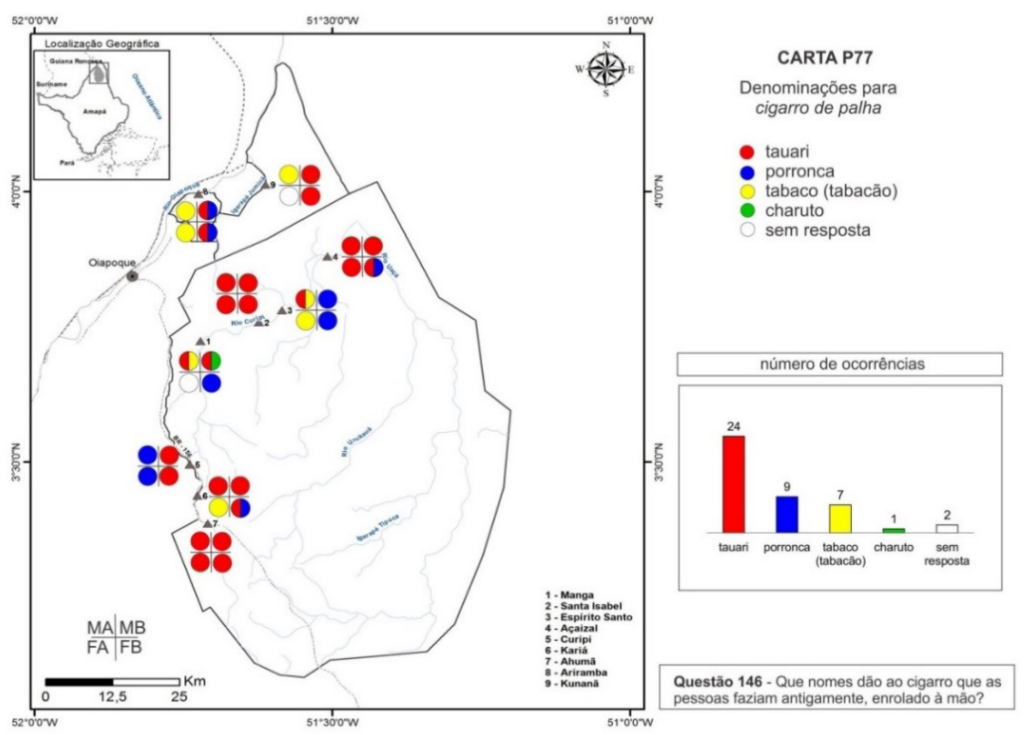

Fonte: Sanches (2020).

A figura acima ilustra as denominações para cigarro de palha em português faladas pelos Karipuna do Amapá. Para obtenção das respostas, foi perguntado aos colaboradores indígenas qual o nome dado para aquele "cigarro que as pessoas faziam antigamente, enrolado à mão". As respostas registradas foram: tauari, porronca, tabaco (tabacão) e charuto. A variante porronca apareceu com 09 ocorrências, distribuídas nos pontos 01 (Manga), 03 (Espírito Santo), 04 (Açaizal), 05 (Curipi), 06 (Kariá) e 08 (Ariramba). Para a variante tabaco (tabacão) foram registradas sete (07) ocorrências, mencionada nos pontos 01, 03, 06, 08 e 09. Por último, a variante charuto apareceu com 01 ocorrência no ponto 02 . Com isso, a variante mais frequente foi tauari com 24 ocorrências, sendo mencionada em todas as comunidades pesquisadas.

Diante do levantamento de variantes lexicais feito para cigarro de palha, com base nos trabalhos expostos aqui, destaca-se a variante tauari, termo dicionarizado como Língua Geral Amazônica (Nheengatu). 
tauari: tavari, a entrecasca de uma espécie de Curataria que serve para mortalha para cigarro, muito usada em todo o interior do Amazonas. Extrai-se cortando a casca do tavarizeiro da largura desejada, batendo-a depois com um macete ou coisa que o valha, até separar a parte externa do líber, e continuando para depois separar as diversas folhas do líber entre si (Stradelli 2014, 496).

A variante tauari, quando comparada a outros estudos geolinguísticos na Amazônia, apresenta uma configuração lexical divergente da identificada em área urbana, uma vez que tauari não foi encontrado nos dados do Atlas Linguístico do Brasil (ALiB) ${ }^{7}$ e tampouco nos do Atlas Linguístico do Amapá (ALAP). No entanto, ao comparar este item lexical com os estudos em áreas indígenas, observa-se que lexia apareceu nos dados de Sanches (2020), de Félix (2019) e de Alves $(2018)^{8}$, com predominância no primeiro estudo, conforme Figura 05.

A presença do uso da variante tauari na fala de colaboradores indígenas no extremo norte do Amapá pode ser explicada por fatores ligados ao ecossistema das comunidades indígenas. Com base no estudo botânico de Procópio et al. (2010), o tauari é uma planta lenhosa da família Lecythidaceae, em que há diferentes espécies, em sua maioria, encontrada no Amazonas. Sobre a distribuição geográfica de espécies de tauari pela Amazônia, foi possível constatar que há também uma espécie de tauari na região da Guiana Francesa que se dispersa pela fronteira, chegando ao Brasil, na região do Oiapoque. Conforme figura a seguir.

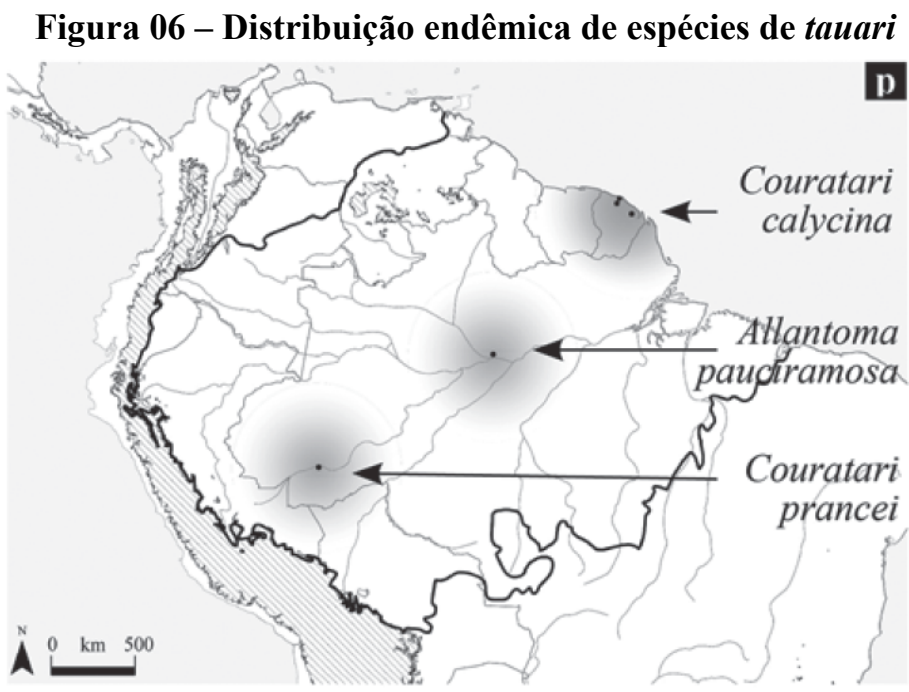

Fonte: Procópio et al. (2010:889).

7 Referente aos dados publicados sobre as capitais brasileiras.

8 Neste trabalho foi registrada como tavarí. 
Este resultado é importante para tentar esclarecer porque a lexia tauari foi uma das variantes que não apareceu nos dados do ALAP e do ALiB. A explicação para isso pode ter relação direta com o habitat da espécie tauari, já que esta predomina em florestas de terra firme e em áreas mais afastadas das cidades, consequentemente, uma espécie de árvore encontrada na floresta amazônica, sendo dela que se extrai o tabaco para fazer o cigarro de taurí. Sabe-se que o maior conhecedor da fauna e flora brasileira é o próprio nativo da região (indígena, quilombola, ribeirinho, seringueiro, etc.), por isso a ausência do uso tauari na fala de colaboradores não indígenas. Destaca-se que entre os colaboradores entrevistados para o ALAP e ALiB estão apenas moradores de cidades urbanas e não urbanas (capitais e não capitais), não foram contempladas comunidades tradicionais. Essa situação também pode explicar a ausência de outras variantes como mostra o Quadro 01.

\section{Quadro 01 - Variantes lexicais para cigarro de palha na Região Norte do Brasil}

\begin{tabular}{|c|c|c|c|c|c|c|}
\hline Estudos $\rightarrow$ & \multirow{3}{*}{$\begin{array}{c}\text { Razky; Costa } \\
(2014) \\
\text { BR/NO }\end{array}$} & \multirow{3}{*}{$\begin{array}{c}\text { Rodrigues } \\
(2017) \\
\text { AP }\end{array}$} & \multirow{3}{*}{$\begin{array}{c}\text { Costa } \\
(2018) \\
\text { PA - MA }\end{array}$} & \multirow{3}{*}{$\begin{array}{c}\text { Alves } \\
(2018) \\
\text { PA }\end{array}$} & \multirow{3}{*}{$\begin{array}{c}\text { Félix } \\
(2019) \\
\text { AM }\end{array}$} & \multirow{3}{*}{$\begin{array}{c}\text { Sanches } \\
(2020) \\
\text { AP }\end{array}$} \\
\hline Variantes $\downarrow$ & & & & & & \\
\hline & & & & & & \\
\hline Porronca & $X$ & - & $\mathrm{X}$ & - & $\mathrm{X}$ & $\mathrm{X}$ \\
\hline cigarro de fumo & $X$ & - & $X$ & $\mathrm{X}$ & - & - \\
\hline cigarro de tabaco & $\mathrm{X}$ & $\mathrm{X}$ & $\mathrm{X}$ & $\mathrm{X}$ & $\mathrm{X}$ & $\mathrm{X}$ \\
\hline cigarro de palha & $\mathrm{X}$ & $\mathrm{X}$ & $\mathrm{X}$ & - & $\mathrm{X}$ & - \\
\hline tauari (tavari) & - & - & - & $\mathrm{X}$ & $\mathrm{X}$ & $\mathrm{X}$ \\
\hline fumo de corda & - & - & $X$ & - & - & - \\
\hline Coringa & - & - & $X$ & - & - & - \\
\hline Barurí & - & - & - & - & $\mathrm{X}$ & - \\
\hline Maratá & - & $\mathrm{X}$ & - & - & - & - \\
\hline cigarro de abade & - & $\mathrm{X}$ & - & - & - & - \\
\hline casca de árvore & - & $\mathrm{X}$ & - & - & - & - \\
\hline Arapiraca & - & $\mathrm{X}$ & - & - & - & - \\
\hline Charuto & - & - & - & - & - & $\mathrm{X}$ \\
\hline
\end{tabular}

Fonte: Elaborado pelo autor.

De acordo com o quadro acima, constata-se que nos dados de Razky e Costa (2014) não foram registradas, na região Norte, as variantes tauarí (tavarí), fumo de corda, coringa, barurí, maratá, cigarro de abade, casca de árvore, arapiraca e charuto. Já nos dados de Rodrigues (2017) não foram encontradas porronca, cigarro de fumo, tauarí (tavari), fumo de corda, coringa, baruri e charuto. Em Costa (2018) não apareceram tauarí (tavarí), barurí, maratá, cigarro de abade, casca de árvore, arapiraca e charuto. Em Alves (2018) houve a ausência de 
porronca, cigarro de palha, fumo de corda, coringa, barurí, maratá, cigarro de abade, casca de árvore, arapiraca e charuto. Em Félix (2019) não foram registradas cigarro de fumo, fumo de corda, coringa, maratá, cigarro de abade, casca de árvore, Arapiraca e charuto. Por fim, em Sanches (2020) não apareceram cigarro de fumo, cigarro de palha, fumo de corda, coringa, baruri, maratá, cigarro de abade, casca de árvore e arapiraca.

Por meio disso, foram identificadas 13 variantes lexicais para denominar cigarro de palha no Norte do Brasil. Algumas são usadas de modo exclusivo em determinadas comunidades indígenas como barurí e coringa em São Gabriel da Cachoeira - AM, arapiraca na Terra Indígena Wajãpi, no Amapá - AP, e entre outras. Estas podem ser classificadas como variantes lexicais divergentes, isto é, são usadas de modo restrito em um microespaço geográfico. Já as variantes cigarro de tabaco e cigarro de palha são usadas tanto em área urbana como em área indígena, isto é, são variantes que coocorrem num macroespaço geográfico e de uso linguístico comum dos falantes de português indígenas e não indígenas, estas podem ser classificadas como variantes lexicais convergentes, uma vez que há o compartilhamento de uso lexical de modo mais abrangente.

A configuração de variantes lexicais convergentes pode ser explicada por meio da expansão da língua portuguesa em área indígena que atua cada vez mais como língua dominante, citam-se como exemplo as lexias cigarro de tabaco e cigarro de palha que se encontram registradas em dicionários de língua portuguesa, como mostra Félix (2018). Já as variantes lexicais divergentes são produtos da resistência linguístico-cultural desses povos, pois, lexias como barurí e arapiraca não aparecem em dicionários da língua portuguesa. Contudo, são variantes usadas conforme o ecossistema das comunidades indígenas, como foi ressaltado anteriormente para o item lexical tauarí.

\section{Algumas considerações}

Este artigo mostrou que nos dados do ALiB-Norte, as variantes mais frequentes na fala de colaboradores não indígenas foram: cigarro de palha, cigarro de fumo, cigarro de tabaco e porronca. Já na área indígena, os estudos geolinguísticos apresentaram 13 variantes lexicais usadas por indígenas para denominar cigarro de palha, a saber: porronca, cigarro de fumo, cigarro de tabaco, cigarro de palha, tauari (tavari), fumo de corda, coringa, baruri, maratá, cigarro de abade, casca de árvore, arapiraca e charuto. Dentre estas, destacam-se as variantes cigarro de palha, cigarro de tabaco e porronca que ocorreram predominante na região Norte e também foram registradas em área indígena.

O resultado da pesquisa possibilitou a classificação de variantes lexicais divergentes e convergentes. Na primeira classificação estão barurí e coringa em São Gabriel da Cachoeira - AM e arapiraca na Terra Indígena Wajãpi, no 
Amapá - AP. Na segunda estão cigarro de tabaco e cigarro de palha, usadas tanto em área urbana como em área indígena.

É certo que ainda é preciso explorar de forma cautelosa a etimologia de certas variantes lexicais, além de buscar novos estudos a fim de confirmar ou refutar a noção de variantes lexicais convergentes e divergentes e a ideia de variante lexical padrão.

\section{Referências}

Alves, F. L. de O. 2018. Estudo geossociolinguístico do português em contato com as línguas Asuriní do Xingu e Araweté. Dissertação (Mestrado). Universidade Federal do Pará.

Cardoso, S. A. M. 2010. Geolinguística: tradição e modernidade. São Paulo: Parábola Editorial.

Cardoso, S. et. al (Orgs.). 2014. Atlas Linguístico do Brasil: vol.1 e vol. 2. Londrina: EDUEL.

Costa, E. O. da. 2018. Estudo geossociolinguístico do léxico do português falado em áreas indígenas de língua Tupi-Guarani nos estados do Pará e Maranhão. Tese (Doutorado). Universidade Federal do Pará.

Cruz, M. L. C. 2004. Atlas Linguístico do Amazonas. Tese (Doutorado em Letras) Universidade Federal do Rio de Janeiro, Rio de Janeiro. V. I e II.

Félix, M. I. de S. 2019. Estudo geossociolinguístico do léxico do Português falado pelos Baré (Nheengatu), Tukano e Baniwa em São Gabriel da Cachoeira (AM). Tese (Doutorado). Universidade Federal do Pará.

Figueiredo Júnior, S. R. 2018. Atlas linguístico pluridimensional do português paulista: níveis semântico-lexical e fonético-fonológico do vernáculo da região do Médio Tietê. Tese (Doutorado). Faculdade de Filosofia, Letras e Ciência Humanas da Universidade de São Paulo. Vol. I.

Maia, E. G. 2018. Atlas Linguístico do Sul Amazonense (ALSAM). Tese (Doutorado). Universidade Estadual de Londrina.

Matos, S. C. de. 2020. Variação lexical na Amazônia Setentrional um estudo comparativo a luz do Atlas Linguístico do Amapá. Trabalho de Conclusão de Curso (Graduação em Letras - Língua Portuguesa) - Universidade Federal do Amapá.

Procópio, L. et al. 2010. As espécies de tauari (Lecythidaceae) em florestas de terra firme da Amazônia: padrões de distribuição geográfica, abundâncias e implicações para a conservação. Acta bot. bras. 24(4), p. 883-897.

Razky, A.; Costa, E. 2014. Os itens lexicais cigarro de palha e toco de cigarro nos atlas linguísticos brasileiros. In: Razky, A. et al. (Org.). Estudos sociodialetais do português brasileiro. São Paulo: Pontes, p. 165-181.

Razky, A.; Ribeiro, C. M. da R.; Sanches, R. D. 2017. Atlas Linguístico do Amapá. São Paulo: Labrador. 
Razky, A.; Sanches, R. 2016. Variação geossocial do item lexical riacho/córrego nas capitais brasileiras. Gragoatá, Niterói, n.40, p. 70-89.

Rodrigues, M. D. G. 2017. Mapeamento lexical do português falado pelos Wajãpi no estado do Amapá: uma abordagem geossociolinguística. Dissertação (Mestrado). Universidade Federal do Pará.

Sá, E. J. de. 2013. Atlas Linguístico de Pernambuco. Tese (Doutorado em Letras) Universidade Federal da Paraíba, João Pessoa - PB.

Sanches, R. 2020. Microatlas Linguístico (português-kheuól) da área indígena Karipuna do Amapá. Tese (Doutorado). Universidade Federal do Pará - UFPA. Programa de Pós-Graduação em Letras, Belém-PA.

Silva, G. A. da. (2019). Carta diatópica: designações para o cigarro enrolado à mão. In: Banco de dados do Atlas Linguístico Topodinâmico e Topoestático do Estado do Tocantins (ALiTTETO). Mensagem para romariodsanches@gmail.com em 08 nov de 2019.

Stradelli, E. 2014. Vocabulário Português-Nheengatu/Nheengatu-Português. CotiaSP: Ateliê Editorial

Thun, H. 2000. La géographie linguistique romane à la fin du XXe siècle. In: CONGRES INTERNATIONAL DE LINGUISTIQUE ET DE PHILOLOGIE ROMANES, 22., 1998, Bruxelles. ACTES... Tübingen: Niemeyer, pp.367-388. v. III. 